\title{
The Relationship Among Academic Social Interaction, Academic Behavior and Academic Achievement of Woldia Secondary School Students: Implication for Quality Education and Psychosocial Support
}

\author{
Yordanos Yibeltal Yedemie $^{1} \quad$ Tilahun Mengistie Yidegi ${ }^{2}$ \\ 1.Bahir Dar University, College of Education and Behavioral Sciences, Department of Psychology, Bahir Dar, \\ Ethiopia \\ 2.Woldia Teacher Education College, Department of Chemistry, Woldia, Ethiopia \\ P.O. Box: +25179
}

\begin{abstract}
The purpose of this study was to determine the level of students' academic social interaction, academic behavior and academic achievement: examine the relationship among academic social interaction, academic behavior and academic achievement: do students' academic social interaction and academic behavior predict students' academic achievement of grade nine and ten students in Woldia Secondary School. The design used in this study was correlational design. The total number of the target population grade nine students in the study area was 1040. Of the total population, 200 grade nine students were selected as the sample of the study using simple random sampling technique. The instruments used in the study were scale questionnaires that measure students' social interaction and academic behavior and documents to access student's academic achievement average score in different school subjects of the first semester of 2011 E.C. One sample t-test, Pearson correlation coefficient and regression analysis were employed as data analysis. The results of one sample t-test demonstrated that the mean value of students' academic social interaction was significantly higher than the mean test value. The mean value of academic behavior was significantly higher than the mean test value. The mean value of students' academic achievement was significantly higher than the mean test value. The results of the Pearson correlation coefficient demonstrated that there was a statistically positive significant correlation between students' academic social interaction and academic achievement. The results of regression analysis revealed that there was statistically significant contribution of academic social interaction and academic behavior to academic achievement. The contribution of academic social interaction found to be positive predictor of academic achievement.
\end{abstract}

Keywords: Social interaction, Academic behavior, Academic achievement

DOI: $10.7176 /$ RHSS/10-15-04

Publication date:August $31^{\text {st }} 2020$

\section{INTRODUCTION}

The major problems facing the world today can be solved only if we improve our understanding of human behavior (Schlinger, 2005). Educational leaders, teachers, school counselors, social workers, school psychologist have long argued that some student were under-preforming academically, because they lack proper social skills (in attentive ness and un prepared during instructional periods, aggressive behavior toward classmates and educational staff, inability to engage cooperative learning and disruptive behavior in class room) which affected their academic skill (studying skill, problem solving skill, critical and decision making skills, mastery and performance skills, task management skills(Rogel, 2014). These all are academic behavior of students who struggled to master good social interaction skills faced more disciplinary consequences when they failed to engage in appropriate behavior. They (students) need to taught directly and systematically skills to succeed in schools (Martens\& Witt 2004, Warger \& Ruther ford, 1996).

Under the realm of behaviorism, the intellect, feelings and emotions of a person inner life are not observable or measurable and therefore not investigated. Thus, a behavioral educator would advocate that effective learning is best accomplished by a change on behavior and relies heavily up on behavioral objectives to accomplish the teaching learning task (Birzer, 2004). Classroom teachers have long recognized the importance of academic social interaction and behavior skills, viewing cooperation, self-control, interpersonal skills study skills motivation and engagement and other social interactions as critical to achieving academic and behavioral success (Lane, Pierson, \& Giver,2003: lane, Webby, \& Cole, 2006). Still, others have argued that students lack of social skills and academic behavior affected their ability to acquire proper academic skills that would allow them to experience a successful educational experience during their years of matriculation in grade k-12 (Akey MT, 2006)

Because the student social interaction are absent, the student is constrained mentally to wonder about during the instructional period, unable to understand and thus concentrate on the subject matter being taught, unable to 
formulate proper questions, the inability to follow along, unable to or fearful to ask questions, clarity illustrations or demonstrations out of shame or embarrassment(Gettinger and Seibert2002),

Toward off embarrassment in front of their peers, some students, because of their lack of academic skills and their inability to constructively engage in class room learning, engaged in the improper behavior such as inattentiveness during instructional periods, and aggressive behavior forward classmates and teachers. Since the student is incapable of engaging in classroom work, the student either is susceptible to an admonishment by the teacher, removal from the classroom work; disciplinary referrals or faced with the possibility of being expelled from school. Some researchers have ventured to conclude that this defensive behavior, on the students' part, is because they lack the ability to function academically, socially, constructively, or academic achievement contribute to the classroom learning, thus leading to unsuccessful in academic achievement (Gettinger \& Seibert 2002).

The process of learning occurs because our learning is associated with a condition and that condition is the environment (Terry Crow, Lian- Ming Tian 2006). As such, we learn from our interactions with our environment or surrounding. Lacking in either or both social interaction and academic behavior in 2 nd cycle primary school students cannot achieve their academic. (Gettinger \& Seibert 2002).

Educational researchers and social educational theorist noticed a steady increase of students exhibiting a lack of academic social interaction (Thompson 2014). The lack of social interaction has been identified as inappropriate student classroom behavior, inattention during instructional periods, aversive relationships and interactions with educators and fellow classmates, and disruptive classroom behavior. The lack of academic social interaction and academic behavior have produced negative consequences in the student's class work and home work, examination, tardiness and absenteeism, and the inability to maintain or sustain social relations among classmates. In addition, the impact of the lack of social interaction and academic behavior on the student academic achievement have shown to existed in the student's ability to engage improper studying skills, problem solving, decision making, content mastery, performance skills and task management skills.

Webby, Symons and Canal, (1998) offered that most junior primary school students engaged in inappropriate classroom behavior because they lacked the social interaction skill to be in the classroom and as a consequence, these students, to avoid looking unintelligent in front of their classmates or peers, engaged in inappropriate behavior they know will get them tossed out of class, into detention, suspended from school, or created aversive interaction with the teacher resulting in the teacher avoiding the student (and unlikely to provide direct education instruction).this in appropriate behavior and negative social interaction have their own impact in student academic achievement

Therefore, in this research the researchers investigated the relationship among social interaction; academic behavior and academic achievement in secondary school students. The study design to answer the following research questions

- Determine the level of students' academic social interaction, academic behavior and academic achievements?

- Is there a relationship among social interaction, academic behavior and academic achievement?

- Does student's social interaction and academic behavior predict student's academic achievement?

\section{METHODS}

The aim of this research is to investigating the relationship between social interaction, academic behavior and student's academic achievement. To achieve its purpose, the research designed principally to be quantitative (i. e. correlation study). The sample size calculated by; Sample size $=n=N / 1+N(.0025)$ then calculating the sample size or respondents are 210. Therefore, from the total study participants (1040) 210 students were used as the sample of the study.

Three types of instruments (social interaction, academic behavior and academic achievement) were used for data collection. Besides questionnaires, document analysis of the average scores of grades $9 \& 10$ students in Woldia Twon 2011 E.C academic year first semester final examination record in all subject areas) were used to gather the necessary data from students.

The social interaction questionnaire consisted of three major parts in the first part the respondent's personal information, in the second part questions related to academic social interaction and the third part consisted of questions related with the students' academic behavior. The scale was adapted from Saxena (2002). This scale has 12 items related to the characteristics of students' social interaction. The other scale was academic behavior related to the characteristics of learning behavior of students. The scale adapted from Saxena (2002). This scale has 10 items related to the characteristics of students' social interaction. Both the instruments had four options such as a little bit, somewhat, very much and extremely.

The statistical analysis was carried out based on the basic research questions that the study aimed to answer. Three statistical techniques have been employed correlation (Pearson product moment co-efficient), used to assess the relationship between social interaction\& academic behavior (predictive variable) on the other hand, and criterion variable academic achievement). 
Thus, whether these predictor variables (Social interaction and academic behavior) predict students' academic achievement was examined. The regression technique was used to see how well social interaction and academic behavior (predictive variable) predict students' academic achievement (criterion variable), to assess the levels of students social interaction, academic behavior and academic achievement employed by one sample t-test and the students' first semester final examination results sum up and the mean score were used to represent students' academic achievement.

\section{RESULTS}

Table 1: Level of grade nine \& ten student's academic social interaction, academic behavior and academic achievement

\begin{tabular}{lcccccc}
\hline Variables & & & t-value & \multicolumn{3}{c}{ Test } \\
\hline Academic social interaction & Mean & SD & & Df & Value & sig \\
Academic behavior & 4.18 & .71 & 23.50 & 199 & 2.5 & .001 \\
Academic achievement & 4.08 & .44 & 34.95 & 199 & 2.5 & .001 \\
\hline
\end{tabular}

As indicated in Table 1 the results of one sample t-test demonstrated that the mean value of students' academic social interaction (4.18) was significantly higher than the mean test value which was 2.5 , This result shows that students' academic social interaction seems above average as perceived by students. Similarly, the results of one sample t-test revealed that the mean value of academic behavior (4.08) was significantly higher than the mean test value which was 2.5. This result shows that students' academic behavior seems above average as reported by students. Likewise, the results of one sample t-test shown that the mean value students' academic achievement (62.11) was significantly higher than the mean test value which was 50 . This result shows that students' academic achievement was at an average level.

The second purpose of this study was to examine whether there exists a significant relationship between students' academic social interaction, academic behavior, and academic achievement. To attain this, objective, Pearson correlation coefficient was computed and the results are presented in Table 2.

Table 2: Relationship between Students' Academic Social Interaction, Academic Behavior and Academic Achievement.

\begin{tabular}{|c|c|c|c|c|}
\hline Variable & Mean & SD & & \\
\hline 1. Academic social interaction & 4.18 & .71 & & \\
\hline 2. Academic behavior & 4.08 & .44 & $.783 *$ & \\
\hline 3. Academic Achievement & 62.11 & 9.09 & $.216^{*}$ & $.140^{*}$ \\
\hline
\end{tabular}

As indicated in Table 2 the results of the Pearson correlation coefficient demonstrated that there was a statistically positive significant correlation between students' academic social interaction and academic achievement $(\mathrm{r}=.216, \mathrm{p}<.05)$. This shows that as students' academic social interaction increases students' academic achievement also increases as well. Similarly, there was statistically significant positive correlation between students' academic behavior and academic achievement $(r=.140, \mathrm{p}<.05)$.

Statistically significant positive correlation was observed between students' academic social interaction and academic behavior $(\mathrm{r}=.783, \mathrm{p}<.05)$. This shows that as students' academic social interaction increases their academic behavior increases.

The third objective of this study was to investigate whether academic social interaction and academic behavior predict students' academic achievement. To achieve this, regression analysis performed and the results are presented in Table 3.

Table3: Model summary of the regression

\begin{tabular}{|l|c|c|c|c|}
\hline Model & R & R Square & Adjusted R Square & Std. Error of the Estimate \\
\hline 1 & $.216^{\mathrm{a}}$ & .047 & .0742 & 8.8946 \\
\hline
\end{tabular}

The result of the regression model shown in Table 3 indicates the value of the regression coefficient $\mathrm{R}=.216$ which indicates that there is a relationship between the independent variables and the dependent variable academic achievement. The $\mathrm{R}$ square was (.047) that explains only $4.7 \%$ of the dependent variable academic achievement by the independent variable's academic social interaction and academic behavior and the remaining are explained by other variables which are not treated in this research and this calls further research. 
Table 4: ANOVA table for significance of the model

\begin{tabular}{|l|l|r|r|r|r|r|}
\hline \multicolumn{1}{|l|}{ Model } & Sum of Squares & Df & Mean Square & \multicolumn{1}{c|}{ F } & Sig. \\
\hline \multirow{4}{*}{1} & Regression & 767.725 & 1 & 767.725 & 9.704 & $.002^{\mathrm{b}}$ \\
\cline { 2 - 7 } & Residual & 15664.664 & 198 & 79.114 & & \\
\cline { 2 - 7 } & Total & 16432.389 & 199 & & & \\
\hline \multicolumn{2}{|l|}{ a. Dependent Variable: academic achievement } \\
\hline \multicolumn{2}{|l}{ b. Predictors: (Constant), social interaction } \\
\hline
\end{tabular}

In Table 4 above the ANOVA reports on the general significance of the model. As P is less than .05 and the calculated $\mathrm{F}$ value is larger than the critical value, therefore, the model is significant. Thus, the combination of the independent variables academic social interaction significantly predicted the dependent variable students' academic achievement of grade nine students of Woldia General Secondary school $\left(\mathrm{F}_{(1,198)}=9.704\right)$.

Table 5: Regression Coefficients

\begin{tabular}{|c|c|c|c|c|c|c|}
\hline \multirow{2}{*}{\multicolumn{2}{|c|}{ Model }} & \multicolumn{2}{|c|}{ Unstandardized Coefficients } & \multirow{2}{*}{$\frac{\text { Standardized Coefficients }}{\text { Beta }}$} & \multirow[b]{2}{*}{$\mathrm{T}$} & \multirow[b]{2}{*}{ Sig. } \\
\hline & & $\mathrm{B}$ & Std. Error & & & \\
\hline \multirow[t]{2}{*}{1} & (Constant) & 50.510 & 3.775 & & 13.379 & .000 \\
\hline & Social interaction & 2.778 & .892 & .216 & 3.115 & .002 \\
\hline
\end{tabular}

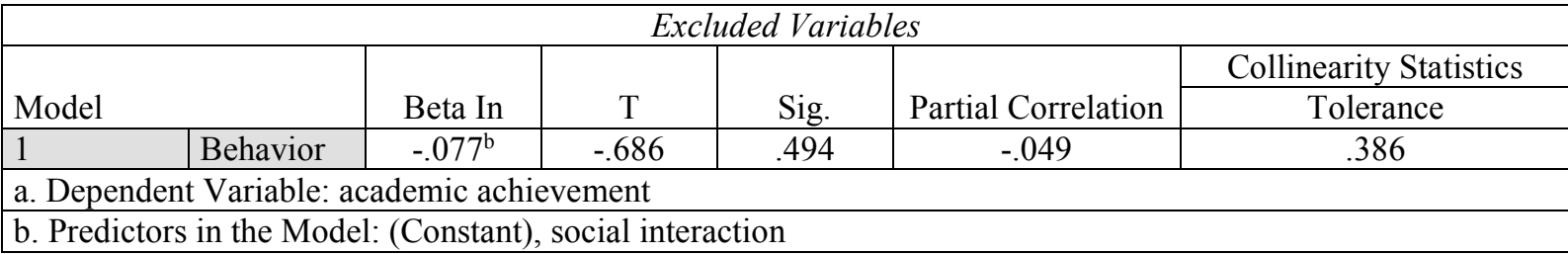

As indicated in Table 5 the results of regression analysis revealed that there was statistically significant contribution of academic social interaction and academic behavior to academic achievement $\mathrm{F}_{(1,198)}=9.704, \mathrm{P}$ $<.002$. The contribution of academic social interaction found to be positive predictor of Academic achievement. But the contribution of students' academic behavior was not statistically significant.

The direct effect of the variables to academic achievement was determined using beta coefficients and the effect of academic social interaction to academic achievement was $(\beta=.216, t=3.115, p<.002)$. The effect of academic behavior to academic achievement was $(\beta=-.077, \mathrm{t}=-.686, \mathrm{p}>.05)$.

The independent contribution of each of the variables to the variance of academic achievement was calculated and the contribution of academic social interaction to the variance of academic achievement was .04665 to the total $\mathrm{R}^{2}$ which was .047 . It is $99.27 \%$ of the total $\mathrm{R}^{2}$. The independent contribution of academic behavior to the variance of academic achievement was negative and negligible. The composite score of $\mathrm{R}^{2}$ was $4.7 \%$.

\section{DISCUSSION}

\section{Students 'academic social interaction, academic behavior \& academic achievement}

The first objective of the study was to determine the level of students' academic social interaction, academic behavior and academic achievement. The results of one sample t-test demonstrated that the mean value of students' academic-social interaction was significantly higher than the mean test value which was 2.5 . This result shows that students' academic-social interaction seems above average as perceived by students. This research finding supported by Thomson (2014) states that academic social interaction seems above average perceived by students $(80 \%)$. This means students in the school environment develop good interaction between themselves. In the same way, Thomson states that students' academic behavior seems above average (50\%). This means students behavior are at good level, this means that student involve themselves in continuous learning have social approval at home, school and also students have positive attitude towards the school, teacher and learning activity

\section{The relationship between students' academic-social interaction, academic behavior \& academic achievement.}

The second purposes of the study were to examine whether there exists a significant relationship between students' academic-social interaction, academic behavior and academic achievement. The results of the Pearson correlation coefficient demonstrated that there was a statistically significant positive correlation between students' academic-social interaction and academic achievement $(r=.216, p<.05)$. This shows that as students' academic-social interaction increases students' academic achievement also increases as well. The research results corresponds to the study of Thomson and Ray \& Elliott, because the research finding shows that there is 
statistically significant positive correlation between students' academic behavior and academic achievement $(\mathrm{r}=$. $140, \mathrm{p}<.05)$. Thomson $(2018)$ states that classroom should be a safe place that is conducive to learning for all students however academic achievement is not always an absolute measure of students intelligence instead a variety of factors such as teacher involvement, parental investment, school quality and student engagement can affect academic achievement and also students behavior plays a measure role in academic achievement as well as the impact of learning environment for the students.

Ray and Elliott (2006) found that student's early childhood positive behavioral characteristics predicted later academic achievement, but this with early negative behavior traits did not exhibits successful academic performance. He concludes academic behavior and academic achievement results influence each other consistently.

\section{The relationship between the independent variables and the dependent variables in students academic achievement}

The third objective of this study was to investigate whether academic-social interaction and academic behavior predict students' academic achievement. The result of the regression model indicates the value of the regression coefficient $\mathrm{R}=.216$ which indicates that there is a relationship between the independent variables and the dependent variable academic achievement. The R square was (.047) that explains only $4.7 \%$ of the dependent variable academic achievement by the independent variables academic-social interaction and academic behavior and the remaining are explained by other variables which are not treated in this research and this call further research(Vacca.et.al, 2011). Route man (2005) contends "students learn more when they are able to talk to one another and be actively involved". In short social interaction is vital to the learning process.

Goodman (1986) stressed that reading, writing, listing and speaking should be kept as a whole. In steady of teaching and learning process each one has to be separated. He promoted that reading, writing, listing and speaking should be incorporated in to everything. Students do throughout the day, because reading, writing and social interaction are part of everyday life in the real world.

Thomson. (2014)) states that students' behavior can affect the ability to learn as well as other students learning environment, he says that academic behavior are independent variable and achievement independent variable predicts dependent variable ( academic achievement) but in this research the contribution of academic behavior statistically significant and social interaction has a positive contribution to academic achievements. (Diperna and Elliott, 2000) states that academic- social interaction is a positive predictor of academic achievement. And in this research the result shows that the independent variable (academic, social interaction) is a positive predictor of dependent variable (academic achievements).

\section{CONCLUSION}

In conclusion, this study suggests that students have socially or collective interactions about their academic activities increase when they are working together with each other. Moreover, students stay closer to do their academic activities in which they are supposed to do in class and out of the class; the better would be their academic achievement. As the results of this, the status of students' academic social interaction and academic behavior improved at large. In addition, the study implied that the predictor variable, academic social interaction, found to be predictor of student academic achievement than academic behavior. This research finding suggests that when students dealing their academic activities together interactively, they perform better than student's academic behavior occurs and persists when they make a request to perform a task.

\section{References}

Adul-Latif, D.L (1998). Improving the social behavior of chronically disruptive students in an elementary school setting. A practicum report presented to the Ed. D program in partial fulfillment of the requirements for the degree of doctor of education, Nova southeastern university (Eric document reproduction services No. ED 425847)

Akey, M.T (2006). School context, student attitudes and academic achievement approaches. Page 31-53. Newyourk; Holt, Reinhart and Winston.

Bandura, A (1977). Self-efficacy; toward a unifying theory of behavioral change psychological review, 84(2), 191-215

Haynes, N. M, Emmons, C and comer, J.P(1994). School climate survey. New haven, CT; Yale child development center, school development program.

Hinshaw (1992). Externalizing behavior problems and academic under achievement in child hood and adolescence; causal relationship and underlying mechanisms; psychological bulletin, 111,127-155

Lavin D.E (1965). The prediction of academic performance, Russell sage foundation, newyork.

Nelson, R.J., (1996). Designing schools to meet the needs of students who exhibit disruptive behavior. Journal of emotional and behavioral disorders,4(3),147-161, July 1996). 
Ralph A et.al, (2010). How student's achievement related to student's behavior and learning style preference

Rogel. (2012). Academic behavior and performance of 3RD year students general Emili Aguinaldo national high school.

Rutter, M (1985). Family and school influence in behavioral development, journal of child psychology and psychiatry, 26 page $340-368$

Thomson, V (2014). How cans behavior affects academics of the student, a web- based forum study in Taiwan.

Yang H. Tang J (2003). Effects of social network on students, performance; a web- based forum study in Taiwan. 